\title{
A SIMPLE PROOF FOR SOME IMPORTANT PROPERTIES OF THE PROJECTION MAPPING
}

\author{
TONG ZHU AND ZHIGANG YU
}

Abstract. In this paper, we give a simple proof for an important property of projection mapping under general $G$-norm.

Mathematics subject classification (2000): 49J99.

Key words and phrases: Variational inequality, projected gradient method, projection and contraction method, projection mapping.

\section{REFERENCES}

[1] P. H. Calamai And J. J. MoRÉ, Projected gradient methods for linearly constrained problems, Math. Programming 39 (1987), 93-116.

[2] B. C. EAVES, On the basic theorem of complementarity, Math. Programming 1 (1971), 68-75.

[3] E. M. GAFNI AND D. P. BERTSEKAS, Two-metric projection methods for constrained optimization, SIAM J. Control Optim. 22 (1984), 936-964.

[4] R. GLOwINSKI, Numerical Methods for Nonlinear Variational Problems, Springer-Verlag, New York, Berlin, Heidelberg, Tokyo, 1984.

[5] A. A. Goldstein, Convex Programming in Hilbert Space, Bull. Amer. Math. Soc. 70 (1964), 709-710.

[6] B. S. HE, A Projection and Contraction Method for a Class of Linear Complementarity Problem and its Application in Convex Quadratic Programming, Appl. Math. Optim. 25 (1992), 247-262.

[7] B. S. HE, A New Method for a Class of Linear Variational Inequalities, Math. Programming 66 (1994), 137-144.

[8] B. S. HE, Solving a Class of Linear Projection Equations, Numer. Math. 68 (1994), 71-80.

[9] B. S. HE, A Class of Projection and Contraction Methods for Monotone Variational Inequalities, Appl. Math. Optim. 35 (1997), 69-76.

[10] B. S. HE, Inexact implicit methods for monotone general variational inequalities, Math. Programming 86 (1999), 199-217.

[11] E. S. LEVITIN AND B. T. POLYAK, Constrained Minimization Problems, USSR Computational Mathematics and Mathematical Physics 6 (1966), 1-50.

[12] J. M. PENG, Equivalence of variational inequality problems to unconstrained minimization, Math. Programming 78 (1997), 347-355.

[13] J. M. PENG AND M. FuKUSHIMA, A hybrid Newton method for solving the variational inequality problem via the D-gap function, Math. Programming 86 (1999), 367-386. 